J. Dairy Sci. 97:4973-4984

http://dx.doi.org/10.3168/jds.2014-8015

() American Dairy Science Association ${ }^{\circledR}, 2014$. Open access under CC BY-NC-ND license.

\title{
A mechanistic model for electricity consumption on dairy farms: Definition, validation, and demonstration
}

\author{
J. Upton, ${ }^{* 1}$ M. Murphy,† L. Shalloo, ${ }^{*}$ P. W. G. Groot Koerkamp, ‡ and I. J. M. De Boer§ \\ *Animal and Grassland Research and Innovation Centre, Teagasc Moorepark Fermoy, Co. Cork, Ireland \\ †Dept. of Process Energy and Transport, Cork Institute of Technology, Cork, Ireland \\ †Farm Technology Group, and \\ §Animal Production Systems Group, Wageningen University, $6700 \mathrm{AH}$ Wageningen, the Netherlands
}

\begin{abstract}
Our objective was to define and demonstrate a mechanistic model that enables dairy farmers to explore the impact of a technical or managerial innovation on electricity consumption, associated $\mathrm{CO}_{2}$ emissions, and electricity costs. We, therefore, (1) defined a model for electricity consumption on dairy farms (MECD) capable of simulating total electricity consumption along with related $\mathrm{CO}_{2}$ emissions and electricity costs on dairy farms on a monthly basis; (2) validated the MECD using empirical data of 1 yr on commercial spring calving, grass-based dairy farms with 45,88 , and 195 milking cows; and (3) demonstrated the functionality of the model by applying 2 electricity tariffs to the electricity consumption data and examining the effect on total dairy farm electricity costs. The MECD was developed using a mechanistic modeling approach and required the key inputs of milk production, cow number, and details relating to the milk-cooling system, milking machine system, water-heating system, lighting systems, water pump systems, and the winter housing facilities as well as details relating to the management of the farm (e.g., season of calving). Model validation showed an overall relative prediction error (RPE) of less than $10 \%$ for total electricity consumption. More than $87 \%$ of the mean square prediction error of total electricity consumption was accounted for by random variation. The RPE values of the milk-cooling systems, water-heating systems, and milking machine systems were less than $20 \%$. The RPE values for automatic scraper systems, lighting systems, and water pump systems varied from 18 to $113 \%$, indicating a poor prediction for these metrics. However, automatic scrapers, lighting, and water pumps made up only $14 \%$ of total electricity consumption across all farms, reducing the overall impact of these poor predictions. Demonstration of the model showed that total farm electricity
\end{abstract}

Received February 4, 2014

Accepted April 7, 2014.

${ }^{1}$ Corresponding author: john.upton@teagasc.ie costs increased by between 29 and $38 \%$ by moving from a day and night tariff to a flat tariff.

Key words: energy, electricity, milk production, mechanistic model

\section{INTRODUCTION}

Grass-based production of $1 \mathrm{~L}$ of milk leaving the farm gate (i.e., including on-farm energy consumption and energy consumption of farm inputs) requires a total energy input of about 2.5 MJ (Upton et al., 2013). On Irish farms, about $12 \%$ of this energy use is represented by electricity consumption, of which $60 \%$ is used in the period with the highest tariff (i.e., from 0900 to $2400 \mathrm{~h}$ ).

Innovations that reduce on-farm electricity consumption might not only reduce total energy consumption of milk production but also electricity costs and $\mathrm{CO}_{2}$ emissions related to energy consumption. Reducing electricity costs might be attractive to farmers, because electricity prices have increased by $32 \%$ in the last 5 yr for European farmers (Eurostat, 2013). Moreover, European dairy farmers are approaching a period of change driven by the removal of the milk quota regimen. Without a quota regimen, farmers are allowed to produce milk unrestrictedly, which is expected to cause increased volatility of the milk price, ultimately resulting in volatility in farm profitability (Lips and Rieder, 2005).

An increase in price volatility warrants attention for cost price minimization. By 2020, however, $80 \%$ of all electricity consumers in Ireland are expected to be connected to the smart grid (CER, 2011). The new Irish electricity grid infrastructure implies a pricing system based on the electricity demand on the national grid, resulting in higher electricity rates during peak periods of consumption and lower rates during off-peak periods. Peak demand is currently from 1700 to $1900 \mathrm{~h}$. If dairy farmers carry out their evening milking during this peak period, they may be exposed to increases in energy costs under the dynamic pricing structure. This dynamic pricing structure, however, could also 
present opportunities to reduce overall energy costs if equipment is managed intelligently to optimize energy consumption in off-peak periods (currently from 0000 to $0900 \mathrm{~h}$ ) (Upton et al., 2013). Evaluation of the potential effect of electricity pricing tariff changes on dairy farm electricity costs requires the development of a specific electricity consumption model.

Similarly, changing one technology in favor of another (e.g., the addition of a water-cooled plate heat exchanger to precooled milk) or one management strategy over another (e.g., milking once or twice per day), however, not only affects electricity costs of producing milk but also energy consumption and associated $\mathrm{CO}_{2}$ emissions. A model that supports decision making of one innovation over another, therefore, should not only evaluate the impact of technology, management practices, and pricing structures on the electricity costs of a farm, but also predict the impact of that innovation on energy consumption and associated $\mathrm{CO}_{2}$ emissions. To our knowledge, such a decision-support model has not been reported. The aim of this study was to define and demonstrate a mechanistic model that enables dairy farmers to explore the impact of a technical or managerial innovation on electricity consumption, associated $\mathrm{CO}_{2}$ emissions, and electricity costs. We, therefore, first defined the model for electricity consumption on dairy farms (MECD). Subsequently, we validated this model by comparing model outputs with empirical data on farm electricity consumption gathered through a physical auditing process. Finally, we demonstrated an application of the model by evaluating the effect of 2 electricity pricing tariffs on total dairy farm electricity costs.

\section{MATERIALS AND METHODS}

\section{Model Definition}

The model described in this paper was developed to predict the electricity consumption, associated $\mathrm{CO}_{2}$ emissions, and electricity costs on dairy farms. The model is a mechanistic mathematical representation of the electricity consumption under the following key headings: milk-cooling system, water-heating system, milking machine system, lighting systems, water pump systems, and winter housing facilities (Figure 1). A monthly time step was chosen because milk production information is available from all commercial farms at the end of each month.

\section{Electricity Consumption Calculations}

The model used key inputs such as monthly herd milk yield, number of cows, and farm infrastructure details (e.g., milk tank size and vacuum pump size, among others) and management practices (e.g., grazing season length), and calculated the electricity consumed by each of the 7 infrastructural systems for $24 \mathrm{~h}$ on 1 d each month. Further key inputs of electricity pricing tariff structure and $\mathrm{CO}_{2}$ emission factors were then applied to compute component running costs and $\mathrm{CO}_{2}$ emissions on a monthly basis. All inputs, calculations, and outputs were based on a month $\times$ daily hour $(12 \times$ 24) matrix structure.

Milk Cooling. The milk-cooling electricity consumption was computed using Equation 1:

$$
Q_{m c}(i, j)=\frac{C_{m} \times \Delta T(i, j) \times M_{m}(i, j)}{C O P(i, j) \times 3,600},
$$

where

$$
\Delta T(i, j)=T_{\text {bulk }}(i, j)-T_{\text {final }}
$$

and

$$
C O P(i, j)=\left[\frac{T_{\text {evap }}}{T_{a m b}(i, j)-T_{\text {evap }}}\right] \times a,
$$

where $Q_{m c}(i, j)=$ predicted energy consumption for milk cooling in month $i(1-12)$ and hour $j(1-24 ; \mathrm{kWh})$, $C_{m}=$ specific heat capacity of milk $\left[\mathrm{kJ} /\left(\mathrm{kg} \cdot{ }^{\circ} \mathrm{C}\right)\right]$, and $\Delta T(i, j)=$ difference in temperature between the milk entering the storage tank $\left[T_{b u l k}(i, j)\right]$ and the milk tank set point $\left(T_{\text {final }} ;{ }^{\circ} \mathrm{C}\right)$. The $T_{\text {bulk }}(i, j)$ was calculated using information about plate cooling from Upton et al. (2010) assuming a milk:water flow ratio of 1:2 in the plate cooler using ground water temperatures from a 100-m borehole well from Goodman et al. (2004). The variable $M_{m}(i, j)$ was the mass of milk in month $i$ and hour $j$ to be cooled $(\mathrm{kg})$. It was assumed that $60 \%$ of the milk was extracted in the morning milking (O'Callaghan and Harrington, 2000). The variable $\operatorname{COP}(i, j)$ was the milk-cooling system coefficient of performance (COP; dimensionless). A submodel was developed to compute the cooling system COP based on a modified Carnot cycle (ideal refrigeration cycle) formula, as described by Henze and Krarti (1998). This approach allows the COP of a specific cooling system to vary according to ambient temperature. It was not designed to represent exactly the vapor compression refrigeration cycle performance of an individual cooling system but rather provide a dynamic element to the COP value of a generalized direct expansion (DX) or ice bank (IB) cooling system. The variable $T_{\text {evap }}$ was the evaporator temperature of the refrigeration system [assumed to be 268 Kelvin (K) for DX and $265 \mathrm{~K}$ for 


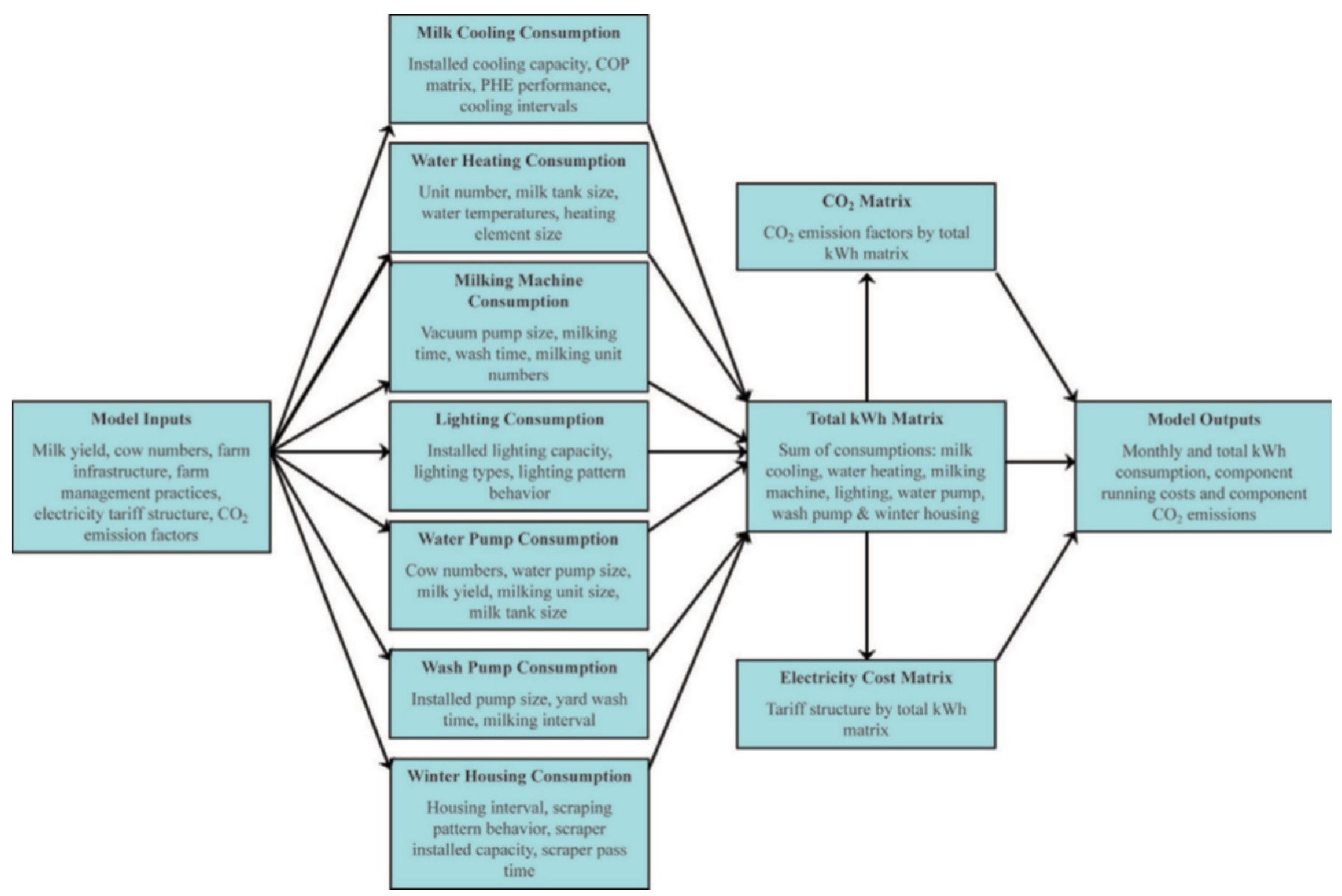

Figure 1. Schematic of milk production electricity consumption model showing the 4 primary sections, illustrated from left to right: (1) inputs, (2) consumption matrix calculations for the 7 main infrastructural systems, (3) consumption summing and tariff application, and (4) outputs. $\mathrm{COP}=$ coefficient of performance; $\mathrm{PHE}=$ plate heat exchanger. Color version available in the online PDF.

IB] and $T_{a m b}(\mathrm{~K})$ was the hourly ambient temperature for 2011 from Met Éireann (Dublin, Ireland; Irish meteorological service); the farms used in the validation of this model were within a 20 mile radius of this weather station. Finally, $a$ was an adjustment factor to account for inefficiencies in real-world systems (assumed 0.10 for this analysis). This approach yielded a range in COP for a DX system of 1.2 to 4.1 and 1.1 to 2.7 for an IB system.

The start time of the cooling system coincided with the time of milking (which was a model input). The duration of cooling was computed with knowledge of the necessary cooling consumption (Equation 1) as well as the installed capacity of the cooling system (Equation 4):

$$
t_{m}(i, j)=Q_{m c}(i, j) / C_{c a p}
$$

where $t_{m}(i, j)=$ time taken to cool the milk (h) and $C_{c a p}=$ capacity of the milk-cooling compressors $(\mathrm{kW})$.
However, on any given day, $Q_{m c}$ can vary due to the ambient temperature effect on the COP, which in turn, varies $t_{m}$. To combat this issue, an approximation of the COP (average COP value across all times and seasons), was used as a first iteration. This allowed the electricity consumption to be placed in the relevant time horizon, which in turn, allowed the final appropriate COP value to be assigned to the cooling consumption on an hourly basis.

Water Heating. The electricity consumed to heat water on a dairy farm was described by Equation 5:

$$
Q_{w h}(i, j)=\frac{C_{w} \times \Delta T(i, j) \times M_{w}(i, j)}{\varepsilon \times 3,600}
$$

where

$$
\Delta T(i, j)=T_{\text {hot }}-T_{\text {cold }}(i, j)
$$

and $Q_{w h}(i, j)=$ predicted energy consumption for heating cleaning water in month $i(1-12)$ and hour $j(1-24)$ 
$(\mathrm{kWh}), C_{w}=$ specific heat capacity of water $(\mathrm{kJ} /$ $\left.\mathrm{kg} \cdot{ }^{\circ} \mathrm{C}\right), \Delta T(i, j)=$ difference in temperature between the water entering the storage tank $\left[T_{\text {cold }}(i, j)\right]$ and the water heater set point $\left(T_{h o t} ;{ }^{\circ} \mathrm{C}\right)$. Borehole water temperatures from Goodman et al. (2004) were used to determine $T_{\text {cold }}$. Guidelines for hot water temperatures and recommended water volumes per milking cluster were taken from the Teagasc Milk Quality Handbook (O'Brien, 2008), and used for $T_{h o t}$. The mass of water to be heated was represented by $M_{w}(i, j ; \mathrm{kg})$ and $\varepsilon$ was the efficiency of the heating system (dimensionless) taken at 0.90 from Upton et al. (2010). The time taken to heat the water was computed using Equation 7:

$$
t_{w}(i, j)=Q_{w h}(i, j) / P_{w h},
$$

where $t_{w}(i, j)=$ time taken to heat the water (h), which was used to determine the specific hours the waterheating system was used, and $P_{w h}=$ installed capacity of the water-heating system $(\mathrm{kW})$. Water heating commenced at $0000 \mathrm{~h}$ (midnight) to coincide with night rate electricity tariffs if the heating system was controlled with a timer, otherwise heating commenced after each milking.

Milking Machine. Electricity consumption of the milking machine was described by the following formula:

$Q_{m m}=\left[\operatorname{Roundup}\left(N_{\text {cows }} / N_{\text {cluster }}\right) \times t_{\text {row }}+t_{\text {wash }}\right] \times P p,[8]$

where $Q_{m m}=$ predicted electricity consumed by the milking machine for 1 milking $(\mathrm{kWh}), N_{\text {cows }}=$ number of cows milked, $N_{\text {cluster }}=$ number of milking clusters in the milking parlor, $t_{\text {row }}=$ cycle time needed to milk $N_{\text {cluster }}$ of cows (h), $P p=$ installed capacity of the milking machine pumps $(\mathrm{kW})$, and $t_{\text {wash }}=$ time required to wash the milking machine clusters and pipes with cleaning fluid after milking. Roundup indicates that the number of cycles needed was rounded to the first integer above the outcome of $N_{\text {cows }} / N_{\text {cluster }}$.

Lighting. Electricity is consumed by lighting on a dairy farm in 3 main areas: (1) milking area, (2) housing facilities, and (3) outdoor areas. Electricity consumed by lighting was then described by Equation 9:

$$
\begin{gathered}
Q_{l}(i, j)=N_{l m} \times Q_{l m} \times T_{l m}(i, j)+N_{h f} \times Q_{l h f} \\
\times T_{l h f}(i, j)+N_{l o d} \times Q_{l o d} \times T_{l o d}(i, j),
\end{gathered}
$$

where $Q_{l}(i, j)=$ predicted electricity consumed by lighting for month $i$ and hour $j(\mathrm{kWh}) ; N_{l m}=$ number of light fittings in the milking facility; $Q_{l m}=$ installed capacity per light unit in the milking facility $(\mathrm{kWh})$, which is calculated using a lookup table of light types; and $T_{l m}(i, j)=$ operating time of lights in the milking facility (h), which was assumed to be equal to the milking time [i.e., Roundup $\left(N_{\text {cows }} / N_{\text {cluster }}\right) \times t_{\text {row }}+t_{\text {wash }}$ ]. This was similar for the remaining variables, where $h f$ $=$ housing facility and $o d=$ outdoor area. $T_{l h f}(i, j)$ and $T_{\text {lod }}(i, j)$ were specified as inputs to the model and describe the operating times of the lights in the housing facilities and the outdoor areas during the months when animals are housed indoors.

Water Pump and Wash Pump. The predicted electricity consumed by the water pumps in month $i$ and hour $j, Q_{w p}(i, j ; \mathrm{kWh})$, was described by the following equation:

$Q_{w p}(i, j)=\left\{\left[V_{m c}(i, j)+V_{d c}(i, j)+V_{w}(i, j)\right] / P_{c}\right\} \times P_{w p}$,

where $V_{m c}(i, j)=$ volume of water consumed by the milking cows $(\mathrm{L})$, which was pumped to water troughs for drinking, and $V_{d c}(i, j)=$ volume of water consumed by the dry cows (L); $V_{m c}$ and $V_{d c}$ were taken from Beede (1992); $V_{w}(i, j)=$ water used for washing and cleaning (L), which was calculated using a combination of data from Beede (1992) and De Boer et al. (2013); $P_{c}=$ total pump capacity (L/hour); and $P_{w p}=$ total pump power $(\mathrm{kW})$, which are model inputs.

Winter Housing. The predicted electricity consumption of the automatic scraping systems in month $i$ and hour $j\left[Q_{a s}(i, j) ; \mathrm{kWh}\right]$ was described by the following equation:

$$
Q_{a s}(i, j)=S_{s t} \times S_{f}(i, j) \times S_{p} \times\left(D_{\text {in }}-D_{\text {out }}\right),
$$

where $S_{s t}=$ scraper sweep time (hours), $S_{f}=$ scraping events in month $i$ and hour $j$ (dimensionless), $S_{p}$ $=$ scraper power $(\mathrm{kW}), D_{\text {in }}=$ housing date of animals (mo), and $D_{\text {out }}=$ turnout date of animals (mo). The months of housing and turnout are converted to integers for the purposed of Equation 11.

\section{Cost and $\mathrm{CO}_{2}$ Calculations}

The 7 electricity consumption matrices described above were summed for month $i$ and hour $j$ to give the total dairy farm consumption matrix $\left(\mathbf{M}_{\mathbf{t}}\right)$. Based on the user model inputs, a $12 \times 24$ matrix was populated for electricity tariffs. Tariffs were compiled from electricity suppliers of the farmers. The $\mathrm{CO}_{2}$ emission factors for electricity production were taken from Howley et al. (2011) and used to populate a $12 \times 24$ matrix. These matrices were multiplied by $\mathbf{M}_{\mathbf{t}}$ to yield the cost matrix $\left(\mathbf{M}_{\mathbf{c}}\right)$ and emission matrix $\left(\mathbf{M}_{\mathbf{e}}\right)$. 


\section{Model Validation}

To validate the performance of the model, the energy consumption of 3 Irish farms were simulated and compared with actual farm data: a small farm (SF) with 45 milking cows, a medium farm (MF) with 88 milking cows, and a large farm (LF) with 195 cows. Farms chosen had spring calving herds in grass-based milk production systems with low supplementary feed input. Actual data from these farms were based on Upton et al. (2013), which yielded detailed electricity consumption data for all major infrastructural systems for all months in 2011, such as milking equipment, milk cooling, manure-handling equipment, water pumps, and winter housing facilities. Details of the farms scale and production levels are presented in Table 1.

\section{Evaluating Model Bias and Precision}

The following parameters were computed to evaluate model bias and precision.

Mean Square Prediction Error. The mean square prediction error (MSPE) comprises the mean bias, line bias, and random variation, and is defined by Equation 12 (Bibby and Toutenburg, 1977):

$\operatorname{MSPE}=\left(A_{m}-P_{m}\right)^{2}+S_{P}^{2}(1-b)^{2}+S_{A}^{2}\left(1-\mathrm{r}^{2}\right),[12]$

where $A_{m}$ and $P_{m}=$ means of the actual and predicted electricity consumption data, respectively; $S_{A}{ }^{2}$ and $S_{P}{ }^{2}=$ variances of the actual and predicted electricity consumption data, respectively; $b=$ slope of the linear regression of actual on predicted; and $\mathrm{r}=$ correlation coefficient of actual and predicted. A mean bias $\left(A_{m}-\right.$ $P_{m}$ ) different from zero indicates that predicted values are respectively consistently higher or lower than the actual values. A low line bias, which is the deviation of the slope of the regression of actual on predicted from unity $(1-b)$, indicates that the model will underpredict at low actual values and overpredict at high actual values, or vice versa. The results of mean bias, line bias, and random variation were calculated as a proportional contribution to each of the 3 components to the total MSPE. The proportional contribution of the mean bias, line bias, and random variation was calculated as the mean bias, line bias, and random variation divided by the MSPE. The relative contribution of the random variation around the regression line $\left(1-r^{2}\right)$ is high if the MECD is predicting electricity consumption with a high level of accuracy. This random variation is due to electricity consumption variation due to farmer and equipment operating behavior.

The Root Mean Square Error. The root mean square error (RMSE; Bibby and Toutenburg, 1977) was calculated as follows:

$$
\operatorname{RMSE}=\sqrt{\mathrm{MSPE}}
$$

The RMSE provides information on the accuracy of the simulation by comparing term by term the actual and predicted data.

Relative Prediction Error. The relative prediction error (RPE; Rook et al., 1990) was calculated as follows:

$$
\mathrm{RPE}=\left(\frac{\mathrm{RMSE}}{A_{m}}\right) \times 100,
$$

where $A_{m}$ is the mean value of the actual data. The $\mathrm{RPE}$ is an expression of the RMSE as a percentage of the actual data. According to Fuentes-Pila et al. (1996), an RPE lower than 10\% indicates a satisfactory prediction, between 10 and $20 \%$ a relatively acceptable prediction, and an RPE greater than $20 \%$ suggests a poor model prediction.

\section{On-Farm Data Used for Model Validation}

In 2011, actual milk production was $255,278 \mathrm{~L}$ for SF, 499,898 L for MF, and 774,089 L for LF, whereas the actual electricity consumption was $8,791 \mathrm{kWh}$ for

Table 1. Mean values of characteristics for 3 farms: small farm (SF), medium farm (MF), and large farm (LF)

\begin{tabular}{lccc}
\hline & \multicolumn{3}{c}{ Farm } \\
\cline { 2 - 4 } Farm characteristic $^{1}$ & $\mathrm{SF}$ & $\mathrm{MF}$ & $\mathrm{LF}$ \\
\hline Farm area (ha) & 48 & 70 & 110 \\
Dairy herd size & 45 & 88 & 195 \\
Stocking density (LU/ha) & 1.68 & 1.90 & 2.43 \\
Milk production (L/yr) & 255,278 & 499,898 & 774,089 \\
Milk production (kg of MS/yr) & 21,429 & 39,286 & 62,199 \\
Production intensity (kg of MS/ha) & 446 & 561 & 565 \\
Milk solids per cow (kg of MS/cow) & 476 & 446 & 319 \\
\hline
\end{tabular}

${ }^{1} \mathrm{LU}=$ livestock units, where $1 \mathrm{LU}$ is equivalent to 1 adult dairy cow; MS = milk solids. 
Table 2. Empirical electricity consumption of each infrastructural component, total consumption and costs for a small farm (SF), medium farm (MF), and large farm (LF) as measured in 2011 (Upton et al., 2013)

\begin{tabular}{lccc}
\hline & \multicolumn{2}{c}{ Farm } \\
\cline { 2 - 4 } Parameter & SF & MF & LF \\
\cline { 2 - 4 } Milk cooling (kWh) & 3,473 & 5,450 & 16,288 \\
Water heating (kWh) & 2,336 & 7,175 & 7,992 \\
Milking machine (kWh) & 2,150 & 3,673 & 5,714 \\
Wash pump (kWh) & $\mathrm{NA}^{1}$ & 149 & $\mathrm{NA}$ \\
Water pump (kWh) & 87 & 1,994 & 2785 \\
Automatic scrapers $(\mathrm{kWh})$ & 563 & 1,653 & $\mathrm{NA}$ \\
Lighting (kWh) & 183 & 983 & 483 \\
Electricity consumption $(W h / L)$ & 34 & 42 & 43 \\
Total electricity consumption $(\mathrm{kWh})$ & 8,791 & 21,099 & 33,262 \\
Electricity costs $(€ / \mathrm{L})$ & 0.0043 & 2,000058 & 0.0051 \\
Annual electricity costs $(€)$ & 1,097 & & 3,942 \\
\hline${ }^{1} \mathrm{NA}=$ not applicable. & &
\end{tabular}

SF, 21,099 kWh for MF, and 33,262 kWh for LF. Table 2 shows the actual electricity consumption $(\mathrm{kWh})$ for each of the 7 main infrastructural systems on each of the 3 farm sizes. On average, milk cooling made up 40\% of the total electricity consumption across all 3 farms (range: 26-49\%), water heating: $28 \%$ (range: 24-34\%), milking machine: $18 \%$ (range: $17-24 \%$ ), wash pump: $0.3 \%$ (range: $0-0.7 \%$ ), water pump: $8 \%$ (range: $1-9 \%$ ), automatic scrapers: $4 \%$ (range: $0-8 \%$ ), and lighting: $3 \%$ (range: $1-5 \%$ ).

The actual electricity consumption and electricity costs per liter of milk were lowest for the SF (i.e., 34 Wh/L and $€ 0.0043 / \mathrm{L}$ ), with $62 \%$ of electricity consumed on the day rate electricity tariff (from 0900 to $2400 \mathrm{~h}$ ). Electricity consumption values were $42 \mathrm{Wh} / \mathrm{L}$ for $\mathrm{MF}$ and $43 \mathrm{Wh} / \mathrm{L}$ for $\mathrm{LF}$, whereas electricity costs were $€ 0.0058 / \mathrm{L}$ for $\mathrm{MF}$ and $€ 0.0051 € / \mathrm{L}$ for $\mathrm{LF}$, with 75 and $68 \%$ of the electricity being consumed on the day tariff, respectively.

\section{Model Demonstration}

To demonstrate the functionality of the model 2 existing tariff matrices were applied to the $\mathbf{M}_{\mathbf{t}}$. First, the farm electricity costs were computed using the farm electricity tariffs from 2011. This took the form of a day and night tariff matrix, where the price of electricity changed from day to night rate at $0000 \mathrm{~h}$ and from night to day rate at $0900 \mathrm{~h}$ (as applied in Ireland in 2013 ), and a flat-rate tariff of $€ 0.18 / \mathrm{kWh}$, which corresponds to the rate for a medium-duty consumer (with consumption of approximately $15,000 \mathrm{kWh}$ of electricity per year) in 2013. This demonstrates the ability of the model to react to changes in the electricity pricing structure. The model also has the ability to evaluate changes in technology applied to each of the 7 infrastructural systems on a dairy farm as well as the ability to evaluate managerial changes, such as once-per-day milking. However, it is outside the scope of this paper to demonstrate all of the functionality of the model.

\section{RESULTS}

\section{Model Predictions}

$\boldsymbol{S F}$. The model predicted a total electricity consumption of $8,498 \mathrm{kWh}$, total electricity costs of $€ 1,108$, and electricity-related emissions of $4,633 \mathrm{~kg}$ of $\mathrm{CO}_{2}$ (Table $3)$. Predictions were made for 5 of the 7 infrastructural systems on a monthly basis (Table 3 ). This farm did not use a wash pump for cleaning purposes. Moreover, the water supply of the SF was sourced, for the majority of the year, from a gravity-fed borehole that did not require pumping. During periods of dry weather or especially high water demand, a secondary pumped supply was used, which consumed only $87 \mathrm{kWh}$ of electricity in 2011 ( $1 \%$ of the overall electricity consumption). Therefore, no prediction was made for this water pump electricity consumption due to the sporadic nature of its operation. The model underpredicted the total electricity consumption of the SF by $293 \mathrm{kWh}(3.3 \%)$ and overpredicted the electricity costs by $€ 11.50(1 \%)$. The MSPE of the total electricity consumption prediction was $5,233 \mathrm{kWh}^{2}$. The proportion of variation made up by the mean bias, line bias, and random variation were $0.11,0.01$, and 0.88 (see Table 4), whereas the RMSE was $72.3 \mathrm{kWh}$ and the RPE was $9.9 \%$. Further details relating to the quality of predictions for the SF are presented in Table 4.

$\boldsymbol{M F}$. The model predicted a total electricity consumption of $20,779 \mathrm{kWh}$, total electricity cost of $€ 2,896$, and electricity-related emissions of $11,329 \mathrm{~kg}$ of $\mathrm{CO}_{2}$. Predictions were made for all of the 7 infrastructural systems on a monthly basis (Table 5). The model underpredicted the total electricity consumption of the MF by $320 \mathrm{kWh}(1.5 \%)$ and underpredicted the total electricity costs by $€ 4.10(0.1 \%)$. The MSPE of 
the total electricity consumption prediction for the MF was $7,127 \mathrm{kWh}^{2}$; the proportion of variation made up by the mean bias, line bias, and random variation were $0.10,0.02$, and 0.88 ; the RMSE was $84.4 \mathrm{kWh}$; and the RPE was $4.8 \%$. Further details relating to the quality of predictions for the MF are presented in Table 4.

$\boldsymbol{L F}$. The model predicted a total electricity consumption of $32,326 \mathrm{kWh}$, total cost of $€ 3,922$, and total electricity-related emissions of $15,147 \mathrm{~kg}$ of $\mathrm{CO}_{2}$. The $\mathrm{LF}$ did not use a standalone wash pump; instead, the main water pump was used for washing purposes. The LF did not use automated scrapers in the winter facility.

The model underpredicted the total electricity consumption by $936 \mathrm{kWh}(2.8 \%)$ and underpredicted total electricity costs by $€ 20.40(0.5 \%)$. Further details of the model predictions of the LF are shown in Table 6 . The MSPE of the total electricity consumption prediction for the LF was $47,997 \mathrm{kWh}^{2}$; the proportion of variation made up by the mean bias, line bias, and random variation were $0.13,0.00$, and 0.87 (Table 4); the RMSE was $219.1 \mathrm{kWh}$; and the RPE was $7.9 \%$. Further details relating to the quality of predictions for the LF are presented in Table 4.

\section{Model Bias and Precision}

Table 4 shows the MSPE, RMSE, and RPE for the 7 infrastructural systems along with the actual and predicted electricity consumption values. The model was most accurate on the MF prediction, delivering an RPE of $4.8 \%$ (RMSE of $84.4 \mathrm{kWh}$ ) for total electricity consumption. About $88 \%$ of the variation was accounted for by the random variation. The RPE for total electricity consumption were $9.9 \%$ for SF (RMSE of 72.3 $\mathrm{kWh}$ ) and $7.9 \%$ for LF (RMSE of $219.1 \mathrm{kWh}$ ). The random variation accounted for a large portion of the MSPE (i.e., 0.88 for SF and 0.87 for LF). The model prediction of milk-cooling consumption, water-heating consumption, and milking-machine consumption all yielded RPE of less than 20\%. These consumptions made up $86 \%$ of total electricity consumption across all 3 farms, which made them the most important items to predict accurately. Automatic scraper consumption, lighting consumption, and water pump consumption proved more difficult to predict. The RPE values varied between 20 and $30 \%$ for water pump predictions, between 42 and $58 \%$ for automatic scraper consumption, and between 18 and $113 \%$ for lighting consumption. However these consumptions, when totaled, made up $14 \%$ of the total electricity consumption of the 3 farms.

\section{Model Demonstration}

Results of the demonstration of the model are presented in Table 7. For this analysis $\mathbf{M}_{\mathbf{t}}$ was multiplied

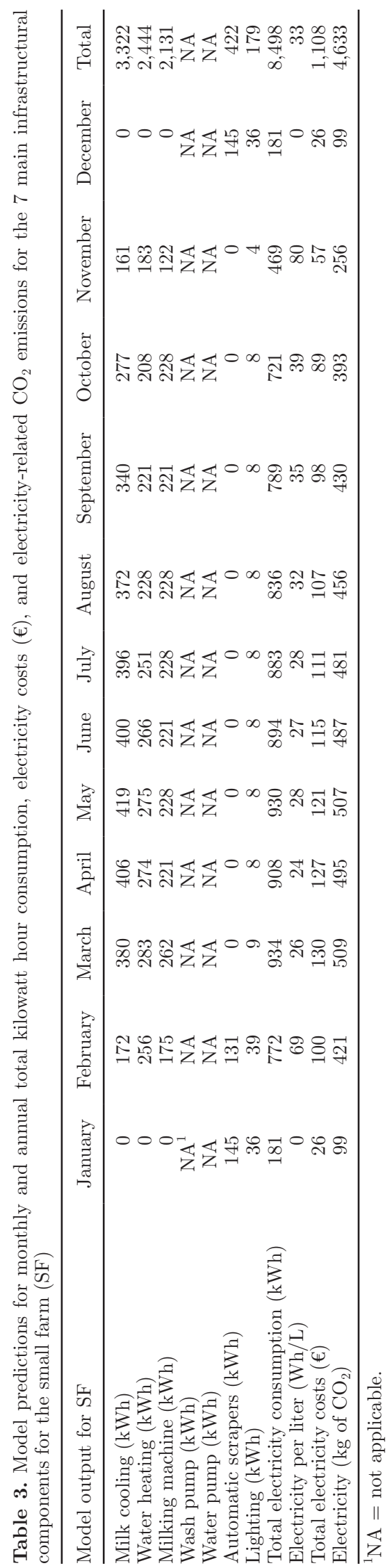

Journal of Dairy Science Vol. 97 No. 8, 2014 
Table 4. Mean square prediction error (MSPE), root mean squared error (RMSE), and relative prediction error (RPE) for the 7 main infrastructural components in the electricity consumption prediction model as well as the prediction of total electricity consumption for the 3 modeled farms: small farm (SF), medium farm (MF), and large farm (LF)

\begin{tabular}{|c|c|c|c|c|c|c|c|c|c|}
\hline Item & $\begin{array}{c}\text { Actual } \\
(\mathrm{A} ; \mathrm{kWh})\end{array}$ & $\begin{array}{l}\text { Predicted } \\
(\mathrm{P} ; \mathrm{kWh})\end{array}$ & $\begin{array}{c}\text { Bias } \\
(\mathrm{P}-\mathrm{A} ; \mathrm{kWh})\end{array}$ & $\begin{array}{l}\text { MSPE } \\
(\mathrm{kWh})^{2}\end{array}$ & \multicolumn{3}{|c|}{ Proportion of MSPE } & $\begin{array}{l}\text { RMSE } \\
(\mathrm{kWh})\end{array}$ & RPE (\%) \\
\hline Milk cooling & 3,473 & 3,322 & -151 & 745 & 0.21 & 0.35 & 0.44 & 27.3 & 9.4 \\
\hline Water heating & 2,336 & 2,444 & 108 & 1,096 & 0.07 & 0.02 & 0.90 & 33.1 & 17.0 \\
\hline Milking machine & 2,150 & 2,131 & -18 & 601 & 0.00 & 0.23 & 0.77 & 24.5 & 13.7 \\
\hline Lighting & 183 & 179 & -4 & 294 & 0.00 & 0.20 & 0.80 & 17.1 & 112.6 \\
\hline Total electricity consumption & 8,791 & 8,498 & -293 & 5,233 & 0.11 & 0.01 & 0.88 & 72.3 & 9.9 \\
\hline \multicolumn{10}{|l|}{ MF } \\
\hline Milk cooling & 5,450 & 5,353 & -97 & 939 & 0.07 & 0.01 & 0.92 & 30.6 & 6.7 \\
\hline Water heating & 7,175 & 7,294 & 119 & 702 & 0.14 & 0.18 & 0.68 & 26.5 & 4.4 \\
\hline Milking machine & 3,673 & 3,628 & -45 & 839 & 0.02 & 0.00 & 0.98 & 29.0 & 9.5 \\
\hline \multicolumn{10}{|l|}{ LF } \\
\hline Milk cooling & 16,288 & 14,898 & $-1,391$ & 63,934 & 0.21 & 0.30 & 0.49 & 252.9 & 18.6 \\
\hline Water heating & 7,992 & 8,303 & 311 & 11,652 & 0.06 & 0.04 & 0.90 & 107.9 & 16.2 \\
\hline Milking machine & 5,714 & 6,124 & 411 & 4,450 & 0.26 & 0.46 & 0.28 & 66.7 & 14.0 \\
\hline Wash pump & NA & NA & NA & NA & NA & NA & NA & NA & NA \\
\hline Water pump & 2,785 & 2,452 & -333 & 4,818 & 0.16 & 0.05 & 0.79 & 69.4 & 29.9 \\
\hline Automatic scrapers & NA & NA & NA & NA & NA & NA & NA & $\mathrm{NA}$ & NA \\
\hline Lighting & 483 & 493 & 10 & 55 & 0.01 & 0.00 & 0.99 & 7.4 & 18.4 \\
\hline Total electricity consumption & 33,262 & 32,326 & -936 & 47,997 & 0.13 & 0.00 & 0.87 & 219.1 & 7.9 \\
\hline
\end{tabular}

${ }^{1} \mathrm{NA}=$ not applicable.

by 2 different electricity price matrices to compute 2 different cost matrices. This approach yielded a model prediction for total farm electricity costs of €1,108 for SF, €2,896 for MF, and €3,922 for LF. Second, applying a flat-rate tariff of $€ 0.18 / \mathrm{kWh}$ demonstrated the effect on total electricity costs if farms were to use a flat-rate electricity tariff instead of the day-and-night-rate tariff. Total electricity costs then increased to $€ 1,530$ for SF, $€ 3,844$ for MF, and $€ 5,046$ for LF.

\section{DISCUSSION}

\section{Model Structure}

Many models have been developed to simulate a range of important impacts of innovations at the farm level. Examples are biophysical and economic impacts on dairy farms (Shalloo et al. 2004; Baudracco et al., 2013), greenhouse gas effects at beef and dairy production systems (O'Brien et al., 2010; Foley et al., 2011), and pasture production effects in grazing systems (O'Neill et al., 2013). At this time, none of these models contains a dedicated electricity consumption submodel, probably because its financial impact was deemed insignificant when energy prices were low and environmental efficiency was not deemed important. However, to evaluate the impact of rising energy prices, or changes to pricing structure, or implementation of technical and managerial innovations on farm profitability and to estimate the environmental effects, a dedicated electricity model is required. Similarly if the MECD were integrated with a whole-farm modeling system, such as in Shalloo et al. (2004), the impact of scenarios such as once-per-day milking versus twiceper-day milking on energy efficiency and energy costs could be examined along with other management strategies, such as spring versus autumn calving or changes in breeding practices by the farmer (e.g., crossbreeding with Jersey cows, which may produce lower milk volumes but similar milk solids per animal).

The mechanistic modeling approach taken in the current study is similar to that taken by Henze et al. (1997), who used a mechanistic approach to describe the operating performance of an ice building system. Other modeling techniques exist, such as pattern recognition regression modeling, which are widely accepted as technologies offering alternative ways to tackle complex and ill-defined problems (Kalogirou, 1999). However, regression models are a generalization tool and are not useful in the analysis of innovations in an 
Table 5. Model predictions for monthly and annual total kilowatt hour consumption, electricity costs $(€)$, and electricity-related $\mathrm{CO}_{2}$ emissions for the 7 main infrastructural components for the medium farm (MF)

\begin{tabular}{|c|c|c|c|c|c|c|c|c|c|c|c|c|c|}
\hline Model output for MF & January & February & March & April & May & June & July & August & September & October & November & December & Total \\
\hline Milk cooling (kWh) & 51 & 308 & 623 & 866 & 672 & 592 & 532 & 485 & 436 & 373 & 294 & 121 & 5,353 \\
\hline Water heating (kWh) & 591 & 563 & 624 & 603 & 624 & 619 & 640 & 640 & 635 & 640 & 549 & 567 & 7,294 \\
\hline Milking machine (kWh) & 216 & 282 & 360 & 349 & 360 & 349 & 360 & 360 & 349 & 312 & 209 & 120 & 3,628 \\
\hline Wash pump (kWh) & 12 & 11 & 12 & 12 & 12 & 12 & 12 & 12 & 12 & 12 & 12 & 12 & 145 \\
\hline Water pump (kWh) & 101 & 109 & 184 & 192 & 185 & 222 & 153 & 145 & 159 & 118 & 128 & 136 & 1,832 \\
\hline Automatic scrapers (kWh) & 315 & 284 & 315 & 0 & 0 & 0 & 0 & 0 & 0 & 0 & 305 & 315 & 1,533 \\
\hline Lighting $(\mathrm{kWh})$ & 66 & 82 & 103 & 91 & 94 & 91 & 94 & 94 & 91 & 82 & 64 & 41 & 994 \\
\hline Total electricity consumption (kWh) & 1,352 & 1,640 & 2,221 & 2,113 & 1,947 & 1,885 & 1,792 & 1,737 & 1,682 & 1,538 & 1,560 & 1,312 & 20,779 \\
\hline Electricity consumption per liter (Wh/L) & 129 & 63 & 38 & 34 & 32 & 26 & 37 & 38 & 33 & 49 & 66 & 106 & 42 \\
\hline Total electricity costs $(€)$ & 173 & 232 & 328 & 330 & 278 & 267 & 244 & 235 & 225 & 200 & 217 & 167 & 2,896 \\
\hline Electricity $\left(\mathrm{kg}\right.$ of $\left.\mathrm{CO}_{2}\right)$ & 737 & 894 & 1,211 & 1,152 & 1,062 & 1,028 & 977 & 947 & 917 & 838 & 850 & 715 & 11,329 \\
\hline
\end{tabular}

Table 6. Model predictions for monthly and annual total kilowatt hour consumption, electricity costs $(€)$, and electricity-related $\mathrm{CO}_{2}$ emissions for the 7 main infrastructural components for the large farm (LF)

\begin{tabular}{|c|c|c|c|c|c|c|c|c|c|c|c|c|c|}
\hline Model output for LF & January & February & March & April & May & June & July & August & September & October & November & December & Total \\
\hline Milk cooling (kWh) & 56 & 682 & 1,121 & 1,739 & 2,275 & 1,870 & 2,034 & 1,779 & 1,739 & 1,102 & 398 & 101 & 14,898 \\
\hline Water heating (kWh) & 669 & 633 & 709 & 675 & 701 & 699 & 717 & 717 & 699 & 717 & 683 & 685 & 8,303 \\
\hline Milking machine (kWh) & 570 & 515 & 570 & 552 & 570 & 552 & 570 & 570 & 552 & 510 & 320 & 271 & 6,124 \\
\hline Wash pump (kWh) & $\mathrm{NA}^{1}$ & NA & NA & NA & NA & $\mathrm{NA}$ & NA & NA & NA & NA & NA & NA & $\mathrm{NA}$ \\
\hline Water pump (kWh) & 7 & 116 & 280 & 325 & 377 & 305 & 282 & 241 & 221 & 174 & 106 & 20 & 2,452 \\
\hline Automatic scrapers (kWh) & NA & NA & NA & NA & NA & NA & NA & NA & NA & NA & NA & NA & NA \\
\hline Lighting $(\mathrm{kWh})$ & 77 & 70 & 41 & 40 & 41 & 40 & 41 & 41 & 40 & 37 & 23 & 0 & 493 \\
\hline Total electricity consumption (kWh) & 1,379 & 2,016 & 2,722 & 3,331 & 3,965 & 3,466 & 3,645 & 3,348 & 3,251 & 2,540 & 1,530 & 1,132 & 32,326 \\
\hline $\begin{array}{l}\text { Electricity consumption per liter } \\
(\mathrm{Wh} / \mathrm{L})\end{array}$ & 589 & 55 & 31 & 32 & 33 & 36 & 41 & 44 & 47 & 46 & 46 & 182 & 42 \\
\hline Total electricity costs $(€)$ & 148 & 243 & 337 & 430 & 494 & 433 & 457 & 415 & 400 & 295 & 160 & 112 & 3,922 \\
\hline Electricity $\left(\mathrm{kg}\right.$ of $\left.\mathrm{CO}_{2}\right)$ & 553 & 910 & 1,272 & 1,615 & 1,953 & 1,681 & 1,773 & 1,611 & 1,564 & 1,171 & 630 & 413 & 15,147 \\
\hline
\end{tabular}

$\stackrel{\varphi}{{ }^{1} \mathrm{NA}=\text { not applicable. }}$ 
Table 7. Total electricity costs $(€)$ and electricity costs per liter of milk produced $(€ / L)$ for a small farm (SF), medium farm $(\mathrm{MF})$, and large farm (LF) for 2 tariff schemes ${ }^{1}$

\begin{tabular}{l}
\cline { 3 - 6 } \\
\cline { 2 - 5 }
\end{tabular}

existing system. For example, it would be possible to forecast electricity use at the farm level, given a forecasted milk yield using a regression model. Many tools exist for the purpose of forecasting milk yields, such as those described by Grzesiak et al. (2006), Olori et al. (1999), and Quinn et al. (2005). However, a regressionbased electricity prediction model would only be valid if the infrastructure installed on the farm remained static because these models are trained to predict the future based on historic performance. For these reasons, a mechanistic approach was taken in this study.

\section{Model Validation}

Relative prediction error values of less than $10 \%$ (9.9, 4.8 , and $7.9 \%$ for the $\mathrm{SF}, \mathrm{MF}$, and $\mathrm{LF}$, respectively) suggest that the MECD described in this paper can be classified as providing acceptable prediction accuracy for total electricity consumption (Fuentes-Pila et al., 1996). This level of accuracy is satisfactory for the intended use of this model as a decision-support tool for dairy farmers because the practical significance of the errors are low (i.e., prediction errors of total annual electricity costs amounted to approximately $€ 11.50$ for $\mathrm{SF}, € 4.10$ for $\mathrm{MF}$, and $€ 20.40$ for $\mathrm{LF}$ ). Moreover, the random variation accounts for $>87 \%$ of the MSPE of the total electricity consumption predictions, indicating that the majority of errors in prediction are due to chance or random causes. This is preferred to having a large portion of errors accounted for by mean or line bias, which would indicate consistent steady-state errors or inadequacies in the structure of the model, respectively. The subpredictions of the 7 infrastructural systems generated mixed-accuracy levels. The milkcooling consumption RPE values were $9.4 \%$ for SF, $6.7 \%$ for $\mathrm{MF}$, and $18.6 \%$ for $\mathrm{LF}$, which also can be classified as satisfactory prediction accuracy (i.e., $<20 \%$ RPE). The water-heating consumptions were predicted with RPE values of $17.0 \%$ for SF, $4.4 \%$ for $\mathrm{MF}$, and $16.2 \%$ for LF; this can be classified as satisfactory prediction accuracy. Similar satisfactory prediction accuracy was achieved for the milking machine consumptions, as the RPE values were $13.7 \%$ for $\mathrm{SF}, 9.5 \%$ for $\mathrm{MF}$, and $14.0 \%$ for LF.

Some poor prediction accuracies were achieved for the water pump, automatic scraper, and lighting consumptions (details in Table 4). These components together, however, made up only $14 \%$ of the total electricity used across the 3 farms; hence, the poor RPE values achieved (especially for automatic scrapers) only slightly influenced the overall model accuracy. However, if this model were to be applied to a confinement dairy system where cows were housed indoors all year round and where the scrapers and lights made up a higher proportion of the total electricity consumption, then the overall accuracy could decline in a more significant fashion.

\section{Sources of Variation}

Variations in prediction accuracy were found with this modeling approach. Here, we will explain how some of the variations might have arisen.

Milk Cooling. The milk-cooling consumption $\left(Q_{m c}\right)$ for a given volume of milk is driven largely by the COP of the cooling system (Equation 3). It is very common for modelers to assume a COP based on manufacturers performance data (Henze et al. 1997; Halvgaard et al. 2012; O'Dwyer et al. 2012; Hong et al. 2012). In the MECD, we accounted for the variation in ambient temperatures. It is possible, however, that the weather data used, which were sourced from a weather station approximately 20 miles away from the farms, did not present the ambient temperature of the air at the cooling compressor on the farms. The largest effect on milk-cooling energy predictions, however, were expected to be due to variations in effectiveness of the milk precooling system throughout the year. If ground water temperatures varied dramatically throughout the year, this would affect prediction accuracies. 
Water Heating. Water-heating electricity consumption $\left(Q_{w h}\right)$ is governed by hot water consumption, initial water temperature, and final hot water temperature. Many farmer-related sources of variation and equipment-related variations exist in this system. The frequency of washing of the milking machine with hot water is a fixed model input (i.e., it remains constant throughout the year). This may not reflect the true washing frequency, which may vary from season to season, causing prediction errors.

Milking Machine. The electricity consumed by the milking machine is influenced primarily by the time spent milking, which is influenced by size of the herd $\left(N_{\text {cows }}\right)$, size of the milking machine $\left(N_{\text {clusters }}\right)$, and the operator row time (RT). Row time can be approximated according to whether the farmer fully or partially prepares the cow teats before milking, as described by O'Brien et al. (2012). However, the model only uses 1 value throughout the year for RT. It is likely that a farmer would adjust RT throughout the year according to weather conditions and stage of lactation. This would introduce errors in the prediction of $Q_{m m}$.

Lighting. The model requires input on the types (e.g., T8 fluorescent, T5 fluorescent, sodium, halogen, and metal halide) and numbers of fittings located in the milking facility, outdoor areas, and winter housing facility. The model assumes that lighting in the milking facility is turned on during milking. A lighting behavior chart is a required model input and this allows the run times of the housing facility lights and outdoor area lights to be quantified. Naturally, the behavior of the farmer with regard to lighting will not follow these patterns in reality, resulting in prediction errors.

Water Pumping. The quantity of electricity consumed by the water pumps is influenced by the quantity of water consumed by the milking facility during and after milking, the water consumed by the dairy cows, and the maintenance water for stock during the year. Drinking water consumed by the dairy herd will vary from day to day and season to season, which will not be picked up by the model, resulting in prediction errors of this metric.

Winter Facilities. Electricity is consumed in the winter housing facilities by automatic manure-handling equipment. An automatic scraper behavior chart is a required model input and this allows the run times of the scraping equipment to be quantified. However, if the scrapers run more or less frequently in reality, then variation will be introduced.

\section{Model Applications}

Farmers are presented with a plethora of alternative technologies and strategies when upgrading infrastruc- ture (especially around milk harvesting technology). The MECD has been developed with an adaptable infrastructure approach in mind, allowing for alternative technologies and managerial changes to be evaluated. Moreover, the MECD could be used to optimize the decision-making process for new technologies at the farm level. Similarly, the effect of milking speed on electricity costs could be evaluated, with variations arising from variations in milking parlor size, milking routine among farmers, or variations in cow type.

Countries such as Estonia, Finland, France, Ireland, Italy, Malta, the Netherlands, Norway, Portugal, Spain, Sweden, and the United Kingdom are all classified as "dynamic movers" in relation to the implementation of smart grid infrastructure. Within these countries, either the mandatory rollout is already decided or major pilot projects are underway to evaluate the feasibility of smart grids (Hierzinger et al., 2012). Countries such as Australia and New Zealand have recognized smart metering as a method of improving resource use efficiency and have carried out some early-stage feasibility studies and cost-benefit analysis calculations (DRET, 2008; Energy Federation of New Zealand, 2010). These developments heighten the importance of energy efficiency and, moreover, increase the need for further analysis of the impact of smart grids on dairy farming, especially in countries where milk production is a substantial or expanding industry. The MECD could be used to account for time of use tariffs or dynamic pricing tariffs, which would provide guidelines to farmers on how best to use these new pricing structures to their advantage.

\section{CONCLUSIONS}

A model was built that simulated the total yearly electricity consumption, electricity consumption of the 7 main infrastructural systems, total electricity costs, and total electricity-related $\mathrm{CO}_{2}$ emissions. This model was validated by comparing the simulated results against actual farm data, using empirical data of farms of varying scale. The model delivered an acceptable RPE of $<10 \%$ for total electricity consumption, with over $87 \%$ of the MSPE of total electricity consumption being accounted for by random variation. These levels of accuracy make the model suitable for application as an advice tool for farmers to improve their energy efficiency and reduce milk-production costs. The usefulness of the model was demonstrated through an electricity tariff change (i.e., from day-and-night rate to flat rate), which showed that total electricity costs would increase by over $30 \%$ if farmers were to use a flat-rate tariff instead of a day and night tariff. This methodology could be used to assess the impact of vari- 
ous time-of-use tariffs or even a dynamic pricing system on total electricity costs in the future.

\section{ACKNOWLEDGMENTS}

We acknowledge INTERREG IVB North-West Europe for financial support through the Dairyman project (http://www.interregdairyman.eu/).

\section{REFERENCES}

Baudracco, J., N. Lopez-Villalobos, C. W. Holmes, E. A. Comeron, K. A. Macdonald, and T. N. Barry. 2013. e-Dairy: A dynamic and stochastic whole-farm model that predicts biophysical and economic performance of grazing dairy systems. Animal 7:870-878.

Beede, D. K. 1992. Water for Dairy Cattle in Large Dairy Herd Management. H. H. Van Horn and C. J. Wilcox, ed. American Dairy Science Association, Savoy, IL.

Bibby, J., and H. Toutenburg. 1977. Prediction and improved estimation in linear models. Wiley, New York, NY.

CER (Commission for Energy Regulation). 2011. Second Consultation on Possible National Rollout Scenarios for the Smart Metering Cost Benefit Analysis CER10197. CER, Dublin, Ireland.

De Boer, I. J. M., I. E. Hoving, T. V. Vellinga, G. W. J. Van de Ven, P. A. Leffelaar, and P. J. Gerber. 2013. Assessing environmental impacts associated with freshwater consumption along the life cycle of animal products: The case of Dutch milk production in NoordBrabant. Int. J. Life Cycle Assess. 18:193-203.

DRET (Department of Resources Energy and Tourism). 2008. Costbenefit analysis of options for a national smart meter roll-out: Phase two-Regional and detailed analyses regulatory impact statement. DRET, Canberra, Australia.

Energy Federation of New Zealand. 2010. Developing our energy potential, New Zealand Energy Efficiency and Conservation Strategy. Energy Federation of New Zealand, Wellington, New Zealand.

Eurostat. 2013. Eurostat energy price tables. Accessed Sep. 10 2013. http://epp.eurostat.ec.europa.eu/portal/page/portal/ energy/data/database.

Foley, P. A., P. Crosson, D. K. Lovett, T. M. Boland, F. P. O'Mara, and D. A. Kenny. 2011. Whole-farm systems modelling of greenhouse gas emissions from pastoral suckler beef cow production systems. Agric. Ecosyst. Environ. 142:222-230.

Fuentes-Pila, J., M. A. DeLorenzo, D. K. Beede, C. R. Staples, and J. B. Holter. 1996. Evaluation of equations based on animal factors to predict intake of lactating Holstein cows. J. Dairy Sci. 79:1562-1571.

Goodman, R., G. Jones, J. Kelly, E. Slowey, and N. O'Neill. 2004 Geothermal Energy Resource Map of Ireland. Sustainable Energy Ireland, Dublin. Ireland.

Grzesiak, W., P. Błaszczyk, and R. Lacroix. 2006. Methods of predicting milk yield in dairy cows-Predictive capabilities of Wood's lactation curve and artificial neural networks (ANNs). Comput. Electron. Agric. 54:69-83

Halvgaard, R., N. K. Poulsen, H. Madsen, and J. B. Jørgensen. 2012. Economic model predictive control for building climate control in a smart grid. Pages 1-6 in Proc. Innovative Smart Grid Technologies (ISGT), 2012 IEEE PES, San Diego, CA. Institute of Electrical and Electronics Engineers (IEEE), New York, NY.

Henze, G. P., R. H. Dodier, and M. Krarti. 1997. Development of a predictive optimal controller for thermal energy storage systems. HVAC\&R Res. 3:233-264.
Henze, G. P., and M. Krarti. 1998. Ice storage system controls for the reduction of operating cost and energy use. J. Sol. Energy Eng. 120:275-281.

Hierzinger, R., M. Albu, H. van Elburg, A. J. Scott, A. Łazicki, L. Penttinen, F. Puente, and H. Sæle. 2012. European Smart Metering Landscape Report, SmartRegions Deliverable 2.1. Accessed May 24, 2013. http://www.energyagency.at/fileadmin/dam/pdf/ projekte/klimapolitik/SmartRegionsLandscapeReport2012.pdf.

Hong, Y.-Y., J.-K. Lin, C.-P. Wu, and C.-C. Chuang. 2012. Multiobjective air-conditioning control considering fuzzy parameters using immune clonal selection programming. IEEE Trans. Smart Grid 3:1603-1610.

Howley, M., E. Dennehy, M. Holland, and B. Ó. Gallachóir. 2011. Energy in Ireland 1990-2010: 2011 report. Energy policy statistical support unit. Sustainable Energy Ireland, Dublin, Ireland.

Kalogirou, S. A. 1999. Applications of artificial neural networks in energy systems - A review. Energy Convers. Manage. 40:1073-1087.

Lips, M., and P. Rieder. 2005. Abolition of raw milk quota in the $\mathrm{Eu}-$ ropean Union: A CGE analysis at the member country level. J. Agric. Econ. 56:1-16.

O'Brien, B. 2008. Teagasc Milk Quality Handbook: Practical Steps to Improve Milk Quality. Teagasc, Fermoy, Ireland.

O'Brien, B., J. Jago, J. P. Edwards, N. Lopez-Villalobos, and F. McCoy. 2012. Milking parlour size, pre-milking routine and stage of lactation affect efficiency of milking in single-operator herringbone parlours. J. Dairy Res. 79:216-223.

O'Brien, D., L. Shalloo, C. Grainger, F. Buckley, B. Horan, and M. Wallace. 2010. The influence of strain of Holstein-Friesian cow and feeding system on greenhouse gas emissions from pastoral dairy farms. J. Dairy Sci. 93:3390-3402.

O'Callaghan, E., and D. Harrington. 2000. Effect of liner design on milking characteristics. Ir. J. Agric. Food Res. 39:383-399.

O'Dwyer, C., R. Duignan, and M. O'Malley. 2012. Modeling demand response in the residential sector for the provision of reserves. Pages 1-8 in Proc. 2012 IEEE PES General Meeting, San Diego, CA. Institute of Electrical and Electronics Engineers (IEEE), New York, NY

O'Neill, B. F., E. Lewis, M. O'Donovan, L. Shalloo, N. Galvin, F. J. Mulligan, T. M. Boland, and R. Delagarde. 2013. Predicting grass dry matter intake, milk yield and milk fat and protein yield of spring calving grazing dairy cows during the grazing season. Animal 7:1379-1389.

Olori, V. E., S. Brotherstone, W. G. Hill, and B. J. McGuirk. 1999. Fit of standard models of the lactation curve to weekly records of milk production of cows in a single herd. Livest. Prod. Sci. 58:55-63.

Quinn, N., L. Killen, and F. Buckley. 2005. Empirical algebraic modelling of lactation curves using Irish data. Ir. J. Agric. Food Res. 44:1-13.

Rook, A. J., M. S. Dhanoa, and M. Gill. 1990. Prediction of the voluntary intake of grass silages by beef cattle. Precision of alternative prediction models. Anim. Prod. 50:455-466.

Shalloo, L., P. Dillon, M. Rath, and M. Wallace. 2004. Description and validation of the Moorepark Dairy System Model. J. Dairy Sci. $87: 1945-1959$

Upton, J., J. Humphreys, P. W. G. Groot Koerkamp, P. French, P. Dillon, and I. J. M. De Boer. 2013. Energy demand on dairy farms in Ireland. J. Dairy Sci. 96:6489-6498.

Upton, J., M. Murphy, P. French, and P. Dillon. 2010. Energy Use on Dairy Farms. Pages 87-97 in Proc. Teagasc Natl. Dairy Conf. Teagasc, Mullingar, Ireland. Teagasc, Fermoy, Ireland. 